\title{
Influence of exercise training on cardiac baroreflex sensitivity in patients with COPD
}

\author{
F. Costes, F. Roche, V. Pichot, J.M. Vergnon, M. Garet, J-C. Barthelemy
}

Influence of exercise training on cardiac baroreflex sensitivity in patients with COPD. F. Costes, F. Roche, V. Pichot, J.M. Vergnon, M. Garet, J-C. Barthelemy. (C) RS Journals Ltd 2004.

ABSTRACT: Decreased spontaneous cardiac baroreflex sensitivity (BRS), which could lead to the onset of cardiovascular events, has been demonstrated in chronic obstructive pulmonary disease patients. This study evaluates the effects of an exercise training programme on BRS.

Twenty-one chronic obstructive pulmonary disease patients (mean \pm SD age $62 \pm 9$ yrs; forced expiratory volume in one second $43.6 \pm 18.1 \%$ of the predicted value) with mild hypoxaemia (arterial oxygen tension $8.96 \pm 1.18 \mathrm{kPa}$ ) were compared to 18 healthy agematched subjects. BRS was calculated as the slope of the baroreflex sequences between spontaneous changes in systolic blood pressure and subsequent consecutive relative risk deviation length, and was measured in the supine position and following head-up tilt for sympathetic stimulation.

Pulmonary function test results and blood gas levels, measured only in patients, did not change after the training programme. Exercise training increased the maximal sustained workload $(16.5 \%)$ and peak oxygen consumption $(20.5 \%)$. Before training, BRS was lower in patients than in controls $\left(2.7 \pm 1.5\right.$ versus $\left.7.8 \pm 4.9 \mathrm{~ms} \cdot \mathrm{mmHg}^{-1}\right)$ and tilting induced a smaller reduction in BRS (13 versus 34\%). After training, BRS increased to $3.4 \pm 2.6 \mathrm{~ms} \cdot \mathrm{mmHg}^{-1}$ in patients but remained lower than in controls. The response to the tilt test remained unchanged after training.

It is concluded that, in chronic obstructive pulmonary disease patients, exercise training is associated with a gain in spontaneous baroreflex sensitivity, reflecting cardiovascular benefits.

Eur Respir J 2004; 23: 396-401.
Cardiorespiratory Function Test Laboratory "GIP Exercice", and Dept of Pneumology and Thoracic Oncology, University Hospital, Saint-Etienne, France.

Correspondence: F. Costes

Service EFCR

Hôpital Nord

CHU Saint Etienne

F42055 Saint Etienne Cedex 2

France

Fax: 33477828447

E-mail: frederic.costes@chu-st-etienne.fr

Keywords: Baroreflex sensitivity cardiovascular adaptation

chronic obstructive pulmonary disease exercise training

Received: April 102003

Accepted after revision: October 232003
The onset of cardiac arrhythmias or stroke is a common occurrence in advanced chronic obstructive pulmonary disease (COPD) [1-3]. Hypoxaemia and the resulting elevated pulmonary arterial pressures are the main factors leading to cardiac involvement, and, consequently, mortality in COPD patients $[4,5]$.

Cardiac autonomic nervous system dysregulation is established in COPD patients. Although the cause is still unclear, several factors could be suspected, including hypoxaemia, poor physical fitness and chronic pulmonary stretch receptor stimulation following pulmonary inflation. PATAKAs et al. [6] first demonstrated decreased pharmacological baroreflex sensitivity (BRS) in 27 COPD patients compared to controls and a significant negative relationship with mean pulmonary arterial pressure. However, the elevated pulmonary arterial pressure did not fully explain this altered BRS. Recently, the role of hypoxia has been demonstrated by the increased BRS in COPD patients with mild hypoxaemia after short-term oxygen supplementation [7]. Others studies have reported an elevated relative frequency of cardiac dysautonomia in these patients, measured by responses to sympathetic or parasympathetic stimuli $[8,9]$.

Cardiac frequency $(f \mathrm{c})$ variability was also found to be decreased in these patients, and the autonomic balance was in favour of predominantly parasympathetic activity $[10,11]$.
STEIN et al. [12] even suggested that $f_{\mathrm{c}}$ variability could be used as a prognostic factor in emphysema. In healthy subjects, as well as in patients with coronary disease, $f$ c variability is influenced by physical training [13-16]. Increases in $f_{\mathrm{c}}$ variability through endurance training in patients with cardiac disease could reduce the occurrence of cardiac arrhythmias.

In COPD patients, exercise training increased exercise tolerance and the ability to sustain a high ventilation level without changes in pulmonary volumes or blood gas levels [17-20]. In order to clarify the relationship between cardiac autonomic nervous activity and pulmonary inflation and exercise conditioning in COPD patients, BRS and $f_{\mathrm{c}}$ variability were measured before and after an exercise training programme in COPD patients, and the results compared to those of normal age-matched subjects.

\section{Patients and methods}

\section{Patients}

Twenty-one patients with mild-to-moderate COPD participated in an 8-week ambulatory pulmonary rehabilitation programme. They had been free of exacerbation of their disease for $\geqslant 1$ month. Patients with chronic cor pulmonale, 
Table 1.-Characteristics of chronic obstructive pulmonary disease (COPD) patients and controls, and pulmonary function and maximal exercise capacity in patients before and after rehabilitation programme

\begin{tabular}{|c|c|c|c|}
\hline & \multicolumn{2}{|c|}{ COPD patients } & \multirow[t]{2}{*}{ Controls } \\
\hline & $\begin{array}{c}\text { Before } \\
\text { programme }\end{array}$ & $\begin{array}{c}\text { After } \\
\text { programme }\end{array}$ & \\
\hline Subjects $n$ & 21 & 21 & 18 \\
\hline Age yrs & $62 \pm 9$ & & $66 \pm 1$ \\
\hline $\mathrm{BMI} \mathrm{kg} \cdot \mathrm{m}^{-2}$ & $26.4 \pm 3.3$ & $26.9 \pm 3.6$ & $25.4 \pm 3.5$ \\
\hline \multicolumn{4}{|l|}{ Pulmonary function } \\
\hline FEV1 L & $1.32 \pm 0.45$ & $1.30 \pm 0.42$ & \\
\hline$\%$ pred & $43.6 \pm 18.1$ & $43.5 \pm 14.5$ & \\
\hline VC L & $2.84 \pm 0.73$ & $2.90 \pm 0.67$ & \\
\hline$\%$ pred & $74.2 \pm 18.7$ & $75.0 \pm 17.9$ & \\
\hline FEV1/VC \% & $47 \pm 12$ & $46 \pm 12$ & \\
\hline RV L & $4.38 \pm 1.57$ & $4.54 \pm 1.42$ & \\
\hline$\%$ pred & $185.6 \pm 62.1$ & $193.1 \pm 56.5$ & \\
\hline TLC L & $7.26 \pm 1.57$ & $7.55 \pm 1.26$ & \\
\hline$\%$ pred & $112.2 \pm 24.1$ & $116.7 \pm 17.3$ & \\
\hline$P \mathrm{a}, \mathrm{O}_{2} \mathrm{kPa}$ & $8.96 \pm 1.18$ & $8.83 \pm 0.93$ & \\
\hline$P \mathrm{a}, \mathrm{CO}_{2} \mathrm{kPa}$ & $4.83 \pm 0.54$ & $5.05 \pm 0.57$ & \\
\hline \multicolumn{4}{|l|}{ Maximal exercise capacity } \\
\hline Workload W & $72.7 \pm 21.9$ & $84.7 \pm 27.8^{* *}$ & \\
\hline Peak $V^{\prime} \mathrm{O}_{2} \mathrm{~mL} \cdot \mathrm{min}^{-1}$ & $1083 \pm 298$ & $1319 \pm 513^{*}$ & \\
\hline $\mathrm{mL} \cdot \mathrm{min}^{-1} \cdot \mathrm{kg}$ body weight ${ }^{-1}$ & $14.1 \pm 3.3$ & $15.2 \pm 4.0$ & \\
\hline$V^{\prime} \mathrm{CO}_{2} \mathrm{~mL} \cdot \mathrm{min}^{-1}$ & $1150 \pm 406$ & $1319 \pm 513^{* *}$ & \\
\hline$V^{\prime} \mathrm{E} \mathrm{L} \cdot \mathrm{min}^{-1}$ & $44.4 \pm 13.6$ & $45.8 \pm 14.6$ & \\
\hline$f_{\mathrm{c}}$ beats $\cdot \min ^{-1}$ & $136 \pm 16$ & $137 \pm 17$ & \\
\hline
\end{tabular}

Data are presented as mean \pm SD. BMI: body mass index; FEV1: forced expiratory volume in one second; VC: vital capacity; RV: residual volume; TLC: total lung capacity; $\mathrm{Pa}_{2} \mathrm{O}_{2}$ : arterial oxygen tension; $\mathrm{Pa}, \mathrm{CO}_{2}$ : arterial carbon dioxide tension; $V^{\prime} \mathrm{O}_{2}$ : oxygen consumption; $V^{\prime} \mathrm{CO}_{2}$ : carbon dioxide production; $\mathrm{V}^{\prime} \mathrm{E}$ : minute ventilation; $f \mathrm{c}$ : cardiac frequency; $\%$ pred: per cent predicted. ${ }^{*}: \mathrm{p}<0.05 ; * *: \mathrm{p}<0.01$.

left ventricular failure, atrial fibrillation or diabetes mellitus were not included. Table 1 presents the characteristics of the patients. The patients were informed of the experimental protocol and gave written informed consent. The protocol was approved by the ethics committee of Saint-Etienne University Hospital (Saint-Etienne, France).

The control group comprised 18 healthy age-matched subjects.

\section{Methods}

Pulmonary function tests and cardiopulmonary exercise testing. These tests were performed only in the patient group. Spirometry, flow/volume curves (Autobox; Sensormedics, Yorba Linda, CA, USA) and resting arterial blood gas level measurements were obtained before and after exercise training. Pulmonary function tests were performed according to European Respiratory Society recommendations [21]. All COPD patients were treated with inhaled $\beta_{2}$-agonists, 18 with inhaled corticosteroids, two with low doses of systemic steroids (prednisolone $5 \mathrm{mg}$ daily) and eight with anticholinergic drugs (inhaled ipratropium bromide). Medications were not modified during the training programme.

Maximal exercise capacity was evaluated before and immediately after training with a symptom-limited incremental exercise test on a cycle ergometer. After a first stage of unloaded cycling, the workload was increased by $10 \mathrm{~W}$ every minute. Minute ventilation $\left(V^{\prime} E\right)$ was measured using a pneumotachograph (Medgraphics, St Louis, MN, USA) calibrated with a 3 -L syringe. Oxygen consumption $\left(\mathrm{V}^{\prime} \mathrm{O}_{2}\right)$ and carbon dioxide production $\left(V^{\prime} \mathrm{CO}_{2}\right)$ were recorded breathby-breath by means of an oxygen and carbon dioxide analyser (CPX-D; Medgraphics). $f_{\mathrm{c}}$ and oxygen saturation (Satlite; Datex, Helsinki, Finland) were monitored continuously during exercise and recovery. Power output and mean $V^{\prime} \mathrm{O}_{2}$, $V^{\prime} \mathrm{CO}_{2}, V^{\prime} \mathrm{E}$ and $f_{\mathrm{c}}$ recorded during the last $30 \mathrm{~s}$ of exercise testing were considered maximal.

Cardiac autonomic nervous system measurements. Spontaneous cardiac baroreflex sensitivity. The electrocardiographic lead with the greatest $\mathrm{R}$-wave amplitude and signal-to-noise ratio was monitored continuously by means of an oscillograph. Finger arterial blood pressure was measured using the volume-clamp method with a noninvasive continuous blood pressure monitor (Finapress 2300; Ohmeda ${ }^{\circledR}$, Englewood, CO, USA). In this technique, the plethysmographic cuff is placed around the middle phalanx of the finger and cuff pressure modulated to maintain transmural pressure effectively at zero. This monitor has been shown to provide reliable beat-to-beat measurement of systolic blood pressure under a wide variety of autonomic testing conditions compared to intraarterial monitoring [22]. All recordings were continuously digitised at a sampling frequency of $500 \mathrm{~Hz}$ after appropriate calibration, stored through Labview $\mathbb{R}$ files (National Instruments, Austin, TX, USA) and transferred off line to

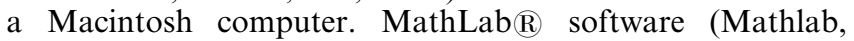
Natick, MA, USA) was used to detect the R-wave peak after transfer of the data, and relative risk (RR) intervals were calculated after removal of any nonsinus rhythm, i.e. ectopic beats, or artefactual segments. RR intervals were paired with the systolic pressure wave amplitude of the preceding beat. Then, the MathLab software selected all sequences of at least three successive heart beats in which concordant increases or decreases in systolic blood pressure and RR interval were detected. Linear regression was performed on each sequence, and a mean regression slope was calculated for the sequences detected during the recording period. This last slope represents cardiac BRS (in milliseconds per millimetre of mercury). Although the vasoactive drug bolus technique seems to be widely considered the standard protocol for BRS assessment in chronic heart failure, the present spontaneous BRS method provides reliable noninvasive assessment of human vagal cardiac BRS [23].

Thoracic movements were recorded using impedance plethysmography; this noninvasive monitoring was not calibrated for volume, permitting measurement of respiratory frequency alone.

Cardiac frequency variability. Spectral analysis was performed using the fast Fourier transform method with a time domain signal, on sliding 256-point Hanning windows. Only normal-to-normal intervals were used, with each interval excluded due to ectopy (prematurity $\geqslant 20 \%$ ) or artefact replaced by maintaining the previous coupling interval level until the next valid coupling interval. Periods with $>5 \%$ ectopic beats were excluded from the analysis. Variables were calculated on 256 consecutive RR intervals extracted from the end of each period of the BRS evaluation.

Power spectrum indices were calculated as recommended by the Task Force of the European Society of Cardiology and the North American Society of Pacing and Electrophysiology [24]. The high-frequency peak of the spectrum $(0.15-0.40 \mathrm{~Hz})$ is known to represent parasympathetic activity; the low-frequency peak $(0.04-0.15 \mathrm{~Hz})$ represents both 
parasympathetic and sympathetic activities. Additional calculations included the low-frequency/high-frequency peak ratio, which represents an evaluation of autonomic nervous system balance (sympathetic/parasympathetic), total frequency power and normalised low- and high-frequency peaks for total frequency power.

Exercise training programme. The patients were enrolled in an 8-week outpatient rehabilitation programme consisting of an endurance exercise training programme three times a week and educational courses. The exercise training programme was designed as follows. After a 5-min warm up period (unloaded cycling), the patients exercised for 30-min sessions during the first week, at a workload corresponding to $60 \%$ of their maximal exercise capacity. The exercise intensity was then progressively increased to reach $75 \%$ of maximal exercise capacity by the end of the second week. For the next 6 weeks, the intensity of the exercise was adjusted to maintain $f_{\mathrm{c}}$ constant, and the duration of the sessions was prolonged to $40 \mathrm{~min}$. Arterial oxygen saturation was controlled during every exercise session, and supplemental oxygen was given through a nasal cannula, as necessary, to maintain arterial oxygen saturation measured by pulse oximetry at $>90 \%$.

\section{Statistical analysis}

All data are presented as mean \pm SD. Analysis of variance was used to compare BRS and $f_{\mathrm{c}}$ variability between patients and controls; the effect of exercise training was also assessed by analysis of variance, followed by Scheffé's test when appropriate.

Linear regression analysis was performed between cardiac autonomic nervous system measurements, as the dependent variables, and pulmonary function test results, blood gas levels or peak $V^{\prime} \mathrm{O}_{2}$, as independent variables.

Statistical significance was set at a p-value of $<0.05$.

\section{Results}

\section{Pulmonary function tests and exercise capacity}

Pulmonary function test and maximal exercise capacity results are presented in table 1 . An obstructive pattern was evident in all patients with mild pulmonary hyperinflation. Resting arterial blood gas levels demonstrated mild hypoxaemia without carbon dioxide retention. No significant change was noted as a result of exercise training.

Maximal exercise capacity was decreased, with a ventilatory limitation to exercise, revealed by a low ventilatory reserve at peak exercise and/or arterial oxygen desaturation. As a result of training, peak workload increased significantly by $16.5 \%$ $(\mathrm{p}<0.01)$ and peak $V^{\prime} \mathrm{O}_{2}$ increased by $20.5 \%(\mathrm{p}<0.05) . V^{\prime} \mathrm{E}$ and $f_{\mathrm{c}}$ were unchanged after training, although peak workload was increased, indicating improved adaptation to exercise. Arterial blood gas levels at peak exercise were not significantly changed, with similar oxygen desaturation (fig. 1).

\section{Spontaneous baroreflex sensitivity}

BRS was dramatically reduced in COPD patients compared to controls $\left(2.7 \pm 1.5\right.$ versus $\left.7.8 \pm 4.9 \mathrm{~ms} \cdot \mathrm{mmHg}^{-1}, \mathrm{p}<0.001\right)$ (fig. 2), and the number of baroreflex sequences was two-fold higher in patients compared to controls $(108.1 \pm 63.0$ versus $52.5 \pm 36.5, \mathrm{p}<0.001)$. Resting $f_{\mathrm{c}}$ was higher in patients than in controls $\left(85.4 \pm 11.2\right.$ versus $64.6 \pm 9.4$ beats $\left.\cdot \mathrm{min}^{-1}, \mathrm{p}<0.001\right)$ (fig. 3). Respiratory frequency was also slightly but significantly higher in patients compared to controls $(16.1 \pm 4.6$ versus $15.6 \pm 4.1$ breaths $\left.\cdot \min ^{-1}, \mathrm{p}<0.001\right)$. Mean arterial blood

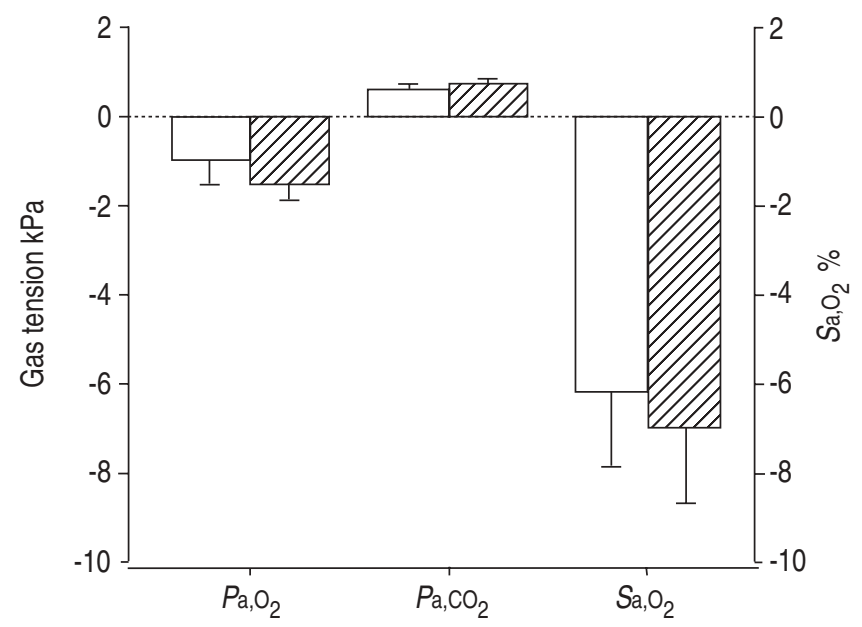

Fig. 1.-Change in arterial blood gas levels at peak exercise before $(\square)$ and after $(\mathbb{Z})$ exercise training. Data are presented as mean \pm SEM. $\mathrm{Pa}_{\mathrm{a}, \mathrm{O}_{2}}$ : arterial oxygen tension; $\mathrm{Pa}_{\mathrm{a}} \mathrm{CO}_{2}$ : arterial carbon dioxide tension; $\mathrm{S}_{\mathrm{a}, \mathrm{O}_{2}}$ : arterial oxygen saturation.
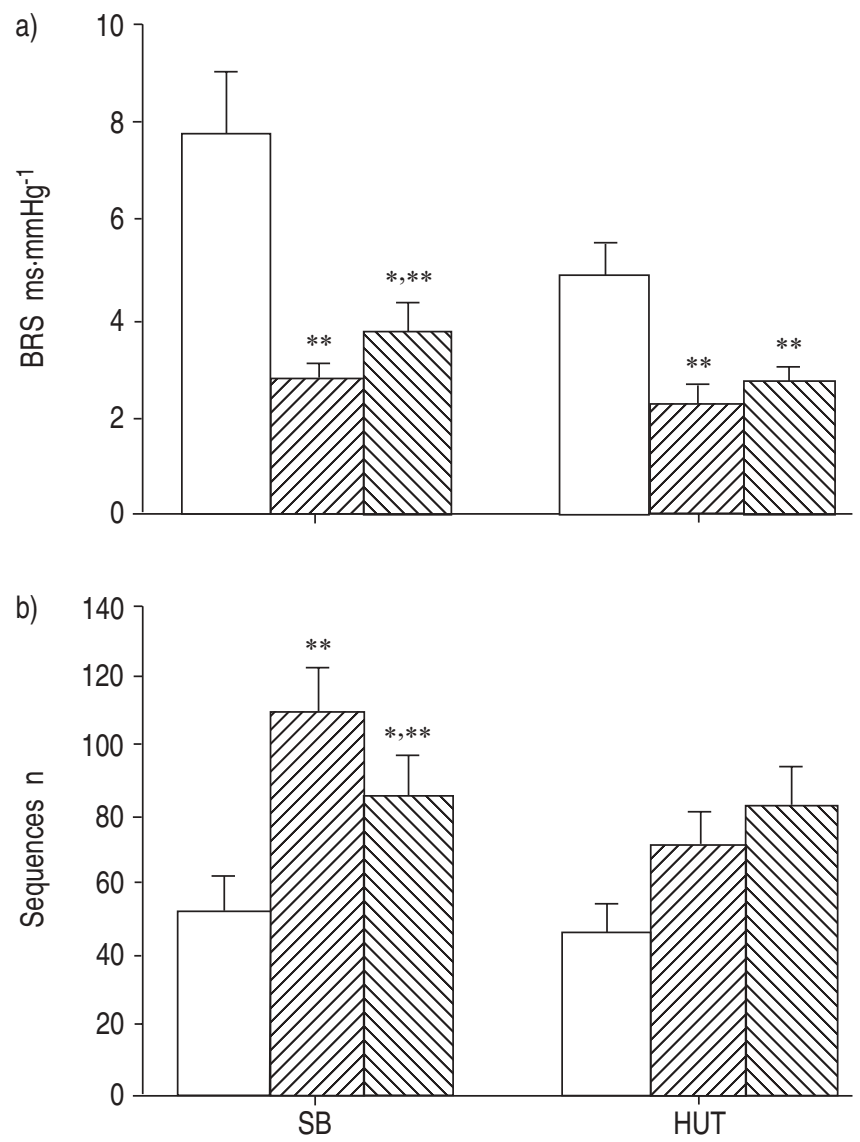

Fig. 2.-a) Baroreflex sensitivity (BRS), and b) number of sequences during BRS measurement in the supine position with a spontaneous breathing (SB) pattern and during a sympathetic activation test (head-up tilt (HUT)) in controls $(\square)$ and chronic obstructive pulmonary disease patients before $(\mathbb{Z})$ and after $(\mathbb{\mathbb { Q }})$ pulmonary rehabilitation. Each sequence corresponded to an activation of the baroreflex loop. Data are presented as mean \pm SEM. *: $\mathrm{p}<0.05$ versus prerehabilitation values; ${ }^{* *}: \mathrm{p}<0.01$ versus controls. 


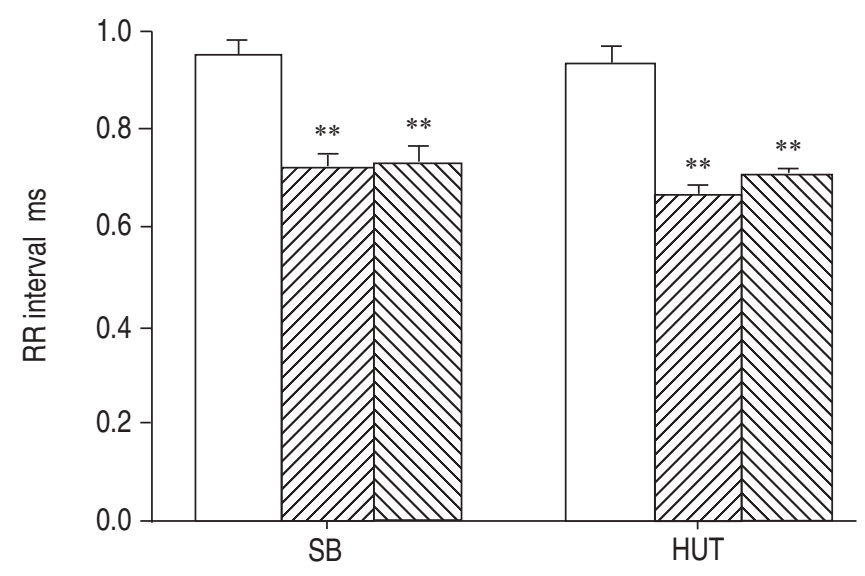

Fig. 3. - Mean relative risk (RR) interval during baroreflex sensitivity measurement in the supine position with a spontaneous breathing (SB) pattern and during a sympathetic activation test (head-up tilt (HUT)) in controls ( $\square$ ) and chronic obstructive pulmonary disease patients before $(\mathbb{Z})$ and after $(\mathbb{Q})$ pulmonary rehabilitation. Data are presented as mean \pm SEM. ${ }^{* *}: \mathrm{p}<0.01$ versus controls.

pressure was not different from that measured in controls $(80.4 \pm 13.1$ versus $79.2 \pm 10.9 \mathrm{mmHg}$ in patients and controls, respectively, $\mathrm{p}=0.8$ ). Mean arterial blood pressure was not significantly altered by training $(73.7 \pm 11.3 \mathrm{mmHg}, \mathrm{p}=0.1)$.

Exercise training increased BRS and decreased the number of sequences, but both remained significantly different from those of control subjects. No change was noticed in mean $f_{\mathrm{c}}$, respiratory frequency or arterial blood pressure following training.

No significant correlation was found between BRS or $f_{\mathrm{c}}$ variability indices and pulmonary function test parameters, peak $V^{\prime} \mathrm{O}_{2}$ or resting $\mathrm{Pa}, \mathrm{O}_{2}$, both before and after training.

\section{Tilt test}

In controls, tilting up induced a clear decrease in BRS $(34 \%, p<0.001)$ with sympathetic stimulation. By contrast, the

Table 2.-Cardiac frequency variability during baroreflex sensitivity measurement in chronic obstructive pulmonary disease (COPD) patients before and after rehabilitation programme and controls

\begin{tabular}{|c|c|c|}
\hline \multicolumn{2}{|c|}{ COPD patients } & Controls \\
\hline $\begin{array}{c}\text { Before } \\
\text { programme }\end{array}$ & $\begin{array}{c}\text { After } \\
\text { programme }\end{array}$ & \\
\hline
\end{tabular}

\begin{tabular}{|c|c|c|c|}
\hline \multicolumn{4}{|l|}{ Spontaneous breathing } \\
\hline Ptot $\mathrm{ms}^{2} \times 10^{-6}$ & $359 \pm 297 *$ & $266 \pm 202 *$ & $557 \pm 485$ \\
\hline $\mathrm{LF} \mathrm{ms}^{2} \cdot \mathrm{Hz}^{-1} \times 10^{-6}$ & $80.2 \pm 58.6$ & $69.9 \pm 50.4$ & $116.5 \pm 15.9$ \\
\hline $\mathrm{HF} \mathrm{ms} \cdot \mathrm{Hz}^{-1} \times 10^{-6}$ & $52.5 \pm 67.3$ & $48.5 \pm 51.7$ & $63.7 \pm 83.2$ \\
\hline LFnu $\mathrm{ms}^{2} \cdot \mathrm{Hz}^{-1} \times 10^{-6}$ & $54.8 \pm 25.9$ & $56.5 \pm 24.9$ & $60.1 \pm 19.4$ \\
\hline HFnu $\mathrm{ms}^{2} \cdot \mathrm{Hz}^{-1} \times 10^{-6}$ & $30.8 \pm 18.4$ & $28.8 \pm 17.8$ & $32.1 \pm 17.8$ \\
\hline $\mathrm{LF} / \mathrm{HF}$ & $3.5 \pm 4.0$ & $3.7 \pm 4.7$ & $2.6 \pm 1.9$ \\
\hline \multicolumn{4}{|l|}{ Head-up tilt } \\
\hline Ptot $\mathrm{ms}^{2} \times 10^{-6}$ & $214 \pm 196^{*}$ & $234 \pm 180^{*}$ & $419 \pm 262$ \\
\hline $\mathrm{LF} \mathrm{ms}^{2} \cdot \mathrm{Hz}^{-1} \times 10^{-6}$ & $55.4 \pm 66.7$ & $56.7 \pm 36.5$ & $110.7 \pm 98.4$ \\
\hline $\mathrm{HF} \mathrm{ms} \mathrm{ms}^{2} \cdot \mathrm{Hz}^{-1} \times 10^{-6}$ & $28.8 \pm 30.4$ & $35.4 \pm 39.5$ & $35.3 \pm 31.4$ \\
\hline LFnu $\mathrm{ms}^{2} \cdot \mathrm{Hz}^{-1} \times 10^{-6}$ & $53.6 \pm 23.1$ & $55.4 \pm 25.5$ & $68.7 \pm 15.8$ \\
\hline HFnu $\mathrm{ms}^{2} \cdot \mathrm{Hz}^{-1} \times 10^{-6}$ & $26.3 \pm 15.5$ & $27.9 \pm 16.1$ & $23.9 \pm 11.1$ \\
\hline $\mathrm{LF} / \mathrm{HF}$ & $3.0 \pm 2.7$ & $3.7 \pm 4.7$ & $4.1 \pm 3.1$ \\
\hline
\end{tabular}

Ptot: total frequency power; LF: low-frequency peak; HF: highfrequency peak; LFnu: normalised LF; HFnu: normalised HF. $*: \mathrm{p}<0.05$ versus controls. reduction in BRS $(13 \%)$ was reduced in patients compared to controls (both $\mathrm{p}<0.001$ ).

Exercise training did not affect significantly the blunted sympathetic stimulation when tilting up.

\section{Fast Fourier transform analysis of cardiac frequency variability}

Owing to major artefacts in RR interval recordings, analysis of $f_{\mathrm{c}}$ variability was not carried out in three patients and one control. In the remaining population, total spectral power was dramatically decreased in patients compared to controls (table 2), both before and after training. However, the autonomous nervous system balance was not different from that in controls, as indicated by the similar ortho- and parasympathetic indexes, and was not altered by training.

In response to the head-up tilt test, the low-frequency/highfrequency peak ratio increased significantly in controls $(71 \%$, $\mathrm{p}<0.001)$, reflecting the sympathetic stimulation, whereas it did not change in COPD patients.

\section{Discussion}

The main finding of the present study was the decrease in BRS in COPD patients along with a blunted sympathetic response to head-up tilt. The beneficial influence of exercise reconditioning on BRS was also shown.

\section{Mechanisms of altered autonomic nervous system activity in pulmonary disease}

The reasons for decreased BRS in pulmonary disease are still unclear. PATAKAS et al. [6] found a negative relationship between pharmacological BRS and pulmonary arterial pressures. In the present study, cardiac echocardiography performed during the routine follow-up of such patients demonstrated normal pulmonary arterial pressures. Alternatively, systemic hypoxia is known to alter BRS in healthy subjects due to induced hyperventilation and chemoreceptor loop activation $[25,26]$. In COPD patients, the effect of relative hypoxia has also been demonstrated recently, by increased BRS after short-term oxygen supplementation [7]. However, the present patients showed only moderate resting hypoxaemia, which could hardly explain the very low BRS measured. It could be argued that oxygen desaturation occurred in most patients during exercise, but the influence of repetitive episodes of hypoxia on BRS has never been evaluated. Exercise-induced oxygen desaturation was unchanged by training, which suggests that hypoxia was not the main determinant of BRS in the present COPD patients.

Elevated systemic blood pressure is also known to alter BRS. As the mean blood pressure measured during BRS was similar in patients and controls, this cannot explain the initially depressed BRS in COPD patients.

A striking feature of the present patients during BRS measurement was the unusually high number of baroreflex sequences. The number of sequences correlated positively with pulmonary hyperinflation (total lung capacity) before exercise training. Moreover, it decreased after training, whereas respiratory frequency was unchanged, suggesting that the intrathoracic pressure levels might explain the stimulation of baroreceptors rather than a higher respiratory frequency, suggesting an influence of pulmonary stretch receptors on BRS activation. However, the lack of change in pulmonary distension with training suggested that it was 
not the sole determinant of autonomic activation, resulting in an abnormal number of BRS sequences.

No significant change was found in respiratory frequency, either between COPD patients and controls or with training. Indeed, changes in respiratory frequency greatly affect BRS. A constant rhythm (usually 12 breaths $\cdot \min ^{-1}$ ) is therefore recommended in order to control respiratory frequency during BRS measurement. It appeared difficult to impose a respiratory frequency on COPD patients, some of whom were very breathless at rest. Measuring BRS at a spontaneous respiratory frequency was therefore the sole solution. As the respiratory frequency did not change with training and was similar in patients and controls, the present authors feel confident that the spontaneous breathing pattern cannot explain the changes in BRS. VAN DE BORNE et al. [27] also demonstrated that hyperventilation was associated with an altered BRS through sympathetic activation. Such adaptation would permit heart and blood pressure to increase simultaneously during exercise. A low basal BRS could thus appear unfavourable for cardiovascular exercise adaptation in these COPD patients, contributing to their poor exercise tolerance.

Bronchial obstruction and pulmonary hyperinflation have also been associated with increased cardiac parasympathetic tone, assessed by $f_{\mathrm{c}}$ variability analysis $[10,11]$. In contrast to these authors, however, no relationship between airway obstruction and indices of $f_{\mathrm{c}}$ variability was found in the present study. The autonomic nervous balance was similar in COPD patients and controls. However, the blunted response to sympathetic stimulation, reported by PAGANI et al. [10], was confirmed. Permanent stimulation of $\beta_{2}$-adrenoreceptors through inhaled bronchodilating sprays certainly plays a role in this lack of response.

\section{Effect of exercise training on autonomic nervous system activity}

Exercise training is known to improve BRS and $f_{\mathrm{c}}$ variability in healthy subjects. In contrast to healthy subjects, COPD patients demonstrated only a modest-though-significant increase in maximal exercise capacity. Moreover, cardiac stimulation was submaximal during the training sessions and is thought to exert only modest influence on cardiovascular adaptation. Although no change was found in maximal $V^{\prime} \mathrm{E}$, pulmonary inflation or respiratory frequency in the present patients as a consequence of training, a change in breathing pattern, especially during the night, cannot be ruled out. This could thus partly explain the improved cardiac autonomic activity. In reference to the other factors influencing BRS, none demonstrated a significant change that could explain the significant increase in BRS measured after training. Thus it appears that exercise reconditioning in patients with poor initial exercise tolerance was a strong stimulus in increasing the baroreflex gain. Improved cardiovascular adaptation to exercise can thus be predicted.

In patients with chronic heart failure, PONIKOwSKI et al. [28] found increased chemoreflex sensitivity, which could exert an inhibitory effect on BRS, through sympathetic stimulation. The same authors also demonstrated that the increased ventilatory response to exercise (high $V^{\prime} \mathrm{E} / V^{\prime} \mathrm{CO}_{2}$ slope) was also significantly related to decreased BRS, a decreased lowfrequency component of $f_{\mathrm{c}}$ variability and increased muscle ergoreflex contribution to ventilation in chronic heart failure patients [29]. Exercise training, in these patients, partly corrected these abnormalities and contributed to an improved ventilatory response to exercise [30]. A change in chemosensitivity has never been reported as a consequence of pulmonary rehabilitation, but the ventilatory adaptations to exercise training are quite similar in COPD and chronic heart failure patients. Consequently, a change in chemosensitivity after training could perhaps explain the increased BRS.

In conclusion, depressed initial baroreflex sensitivity and a beneficial effect of exercise reconditioning as a component of pulmonary rehabilitation were found in chronic obstructive pulmonary disease patients. These autonomic nervous system alterations could contribute to the poor exercise tolerance. Whether this increased baroreflex sensitivity reduces the incidence of cardiovascular events in chronic obstructive pulmonary disease patients remains to be determined.

\section{References}

1. Incalzi RA, Pistelli R, Fuso L, Cocchi A, Bonetti MG, Giordano A. Cardiac arrhythmias and left ventricular function in respiratory failure from chronic obstructive pulmonary disease. Chest 1990; 97: 1092-1097.

2. Gorecka D. Cardiac arrhythmias in chronic obstructive pulmonary disease. Monaldi Arch Chest Dis 1997; 52: 278281.

3. Shih H, Webb C, Conway W, Peterson E, Tilley B, Goldstein S. Frequency and significance of cardiac arrhythmias in chronic obstructive lung disease. Chest 1988; 94: 4448.

4. Nocturnal Oxygen Therapy Trial Group. Continuous or nocturnal oxygen therapy in hypoxemic chronic obstructive lung disease: a clinical trial. Ann Intern Med 1980; 93: 391398.

5. Incalzi RA, Fuso L, De Rosa M, et al. Electrocardiographic signs of chronic cor pulmonale: a negative prognostic finding in chronic obstructive pulmonary disease. Circulation 1999; 99: 1600-1605.

6. Patakas D, Louridas G, Kakavelas E. Reduced baroreceptor sensitivity in patients with chronic obstructive pulmonary disease. Thorax 1982; 37: 292-295.

7. Bartels M, Gonzalez J, Kim W, De Meersman R. Oxygen supplementation and cardiac-autonomic modulation in COPD. Chest 2000; 118: 691-696.

8. Hjalmarsen A, Aasebo U, Aleksandersen G, Jorde R Cardiovascular responses to tests for autonomic dysfunction in patients with chronic obstructive pulmonary disease with and without continuous long-term oxygen therapy. J Auton Nerv Syst 1996; 60: 169-174.

9. Stewart A, Waterhouse J, Howard P. Cardiovascular autonomic nerve function in patients with hypoxaemic chronic obstructive pulmonary disease. Eur Respir J 1991; 4: 1207-1214.

10. Pagani M, Lucini D, Pizzinelli P, et al. Effects of aging and of chronic obstructive pulmonary disease on RR interval variability. J Auton Nerv Syst 1996; 59: 125-132.

11. Volterrani M, Scalvini S, Mazzuero G, et al. Decreased heart rate variability in patients with chronic obstructive pulmonary disease. Chest 1994; 106: 1432-1437.

12. Stein $\mathrm{P}, \mathrm{Nelson} \mathrm{P}$, Rottman $\mathrm{J}$, et al. Heart rate variability reflects severity of COPD in PiZ $\alpha_{1}$-antitrypsin deficiency. Chest 1998; 113: 327-333.

13. Dekker JM, Schouten EG, Klootwijk P, Pool J, Swenne CA, Kromhout D. Heart rate variability from short electrocardiographic recordings predicts mortality from all causes in middle-aged and elderly men. The Zutphen Study. Am J Epidemiol 1997; 145: 899-908.

14. Seals DR, Chase PB. Influence of physical training on heart rate variability and baroreflex circulatory control. J Appl Physiol 1989; 66: 1886-1895.

15. Pichot V, Busso T, Roche F, et al. Autonomic adaptations to intensive and overload training periods: a laboratory study. Med Sci Sports Exerc 2002; 34: 1660-1666.

16. Coats A, Adamopoulos S, Radaelli A, et al. Controlled trial of physical training in chronic heart failure. Circulation 1992; 85: 2119-2131. 
17. Salman G, Mosier M, Beasley B, Calkins D. Rehabilitation for patients with chronic obstructive pulmonary disease: meta-analysis of randomized controlled trials. J Gen Intern Med 2003; 18: 213-221.

18. Casaburi R, Patessio A, Ioli F, Zanaboni S, Donner C, Wasserman K. Reductions in exercise lactic acidosis and ventilation as a result of exercise training in patients with obstructive lung disease. Am Rev Respir Dis 1991; 143: 9-18.

19. Lareau SC, ZuWallack R. Pulmonary rehabilitation. Am J Respir Crit Care Med 1999; 159: 1666-1682.

20. Casaburi R, Petty TL. Principles and Practice of Pulmonary Rehabilitation. Philadelphia, PA, W.B. Saunders, 1993.

21. Quanjer PH, Tammeling GJ, Cotes JE, Pedersen OF, Peslin R, Yernault J-C. Lung volumes and forced ventilatory flows. Report Working Party Standardization of Lung Function Tests, European Community for Steel and Coal. Eur Respir J 1993; 6: Suppl. 16, 5-40.

22. Parati G, Casadei R, Gropelli A, Di Rienzo M, Mancia G. Comparison of finger and intra-arterial blood pressure monitoring at rest and during laboratory testing. Hypertension 1989; 13: 647-655.

23. Parlow J, Viale JP, Annat G, Hughson R, Quintin L. Spontaneous cardiac baroreflex in humans. Comparison with drug-induced responses. Hypertension 1995; 25: 1058-1068.

24. Task Force of the European Society of Cardiology and the North American Society of Pacing and Electrophysiology. Heart rate variability: standards of measurement, physiological interpretation and clinical use. Circulation 1996; 93: 1043-1065.

25. Sagawa S, Torii R, Nagawa K, Wada F, Endo Y, Shiraki K. Carotid baroreflex control of heart rate during acute exposure to simulated altitudes of 3,800 and $4,300 \mathrm{~m}$. $\mathrm{Am}$ J Physiol 1997; 273: R1219-R1223.

26. Roche F, Reynaud C, Garet M, Pichot V, Costes F, Barthélémy JC. Cardiac baroreflex control in humans during and immediately after brief exposure to simulated high altitude. Clin Physiol 2002; 22: 301-306.

27. Van de Borne P, Mezzetti S, Montano N, Narkiewicz K, Degaute JP, Somers VK. Hyperventilation alters arterial baroreflex control of heart rate and muscle sympathetic nerve activity. Am J Physiol Heart Circ Physiol 2000; 279: H536-541.

28. Ponikowski P, Chua TP, Anker SD, et al. Peripheral chemoreceptor hypersensitivity: an ominous sign in patients with chronic heart failure. Circulation 2001; 104: 544-549.

29. Ponikowski P, Francis D, Piepoli M, et al. Enhanced ventilatory response to exercise in patients with chronic heart failure and preserved exercise tolerance. Circulation 2001; 103: 967-972.

30. Piepoli M, Clark A, Volterrani M, Adamopoulos S, Sleight P, Coats A. Contribution of muscle afferents to the hemodynamic, autonomic, and ventilatory response to exercise in patients with chronic heart failure: effects of physical training. Circulation 1996; 93: 940-952. 